\title{
Protein Intake Recommendation for Korean Older Adults to Prevent Sarcopenia: Expert Consensus by the Korean Geriatric Society and the Korean Nutrition Society
}

Hee-Won Jung ${ }^{1}$, Sun-Wook Kim², II-Young Kim ${ }^{3}$, Jae-Young Lim ${ }^{4,5}$, Hyoung-Su Park ${ }^{6}$, Wook Song ${ }^{7}$, Hyung Joon Yoo ${ }^{8}$, HakChul Jang ${ }^{2,5}$, Kirang Kim ${ }^{9}$, Yongsoon Park ${ }^{10}$, Yoon Jung Park ${ }^{11}$, Soo Jin Yang ${ }^{12}$, Hae-Jeung Lee ${ }^{13}$, Chang Won Won ${ }^{14}$; for the Sarcopenia-Frailty Study Group of the Korean Geriatric Society and the Korean Nutrition Society

${ }^{1}$ Graduate School of Medical Science and Engineering, Korea Advanced Institute of Science and Technology (KAIST), Daejeon, Korea

${ }^{2}$ Department of Internal Medicine, Seoul National University Bundang Hospital, Seongnam, Korea

${ }^{3}$ Lee Gil Ya Cancer and Diabetes Institute, Gachon University School of Medicine, Incheon, Korea

${ }^{4}$ Rehabilitation Medicine, Seoul National University Bundang Hospital, Seongnam, Korea

${ }^{5}$ Seoul National University College of Medicine, Seoul, Korea

${ }^{6}$ Sarcopenia Research Center, Maeil Innovation Center, Maeil Dairies Co., Ltd., Pyeongtaek, Korea

${ }^{7}$ Institute of Sport Science, Institute on Aging, Seoul National University, Seoul, Korea

${ }^{8}$ Endocrine Division, Department of Internal Medicine, CM Hospital, Seoul, Korea

${ }^{9}$ Department of Food Science and Nutrition, Dankook University, Seoul, Korea

${ }^{10}$ Department of Food and Nutrition, Hanyang University, Seoul, Korea

${ }^{11}$ Department of Nutritional Science and Food Management, Ewha Womans University, Seoul, Korea

${ }^{12}$ Department of Food and Nutrition, Seoul Women's University, Seoul, Korea

${ }^{13}$ Department of Food and Nutrition, Gachon University, Seongnam, Korea

${ }^{14}$ Department of Family Medicine, Kyung Hee University Medical Center, Seoul, Korea

Corresponding Author:

Chang Won Won, MD, PhD

https://orcid.org/0000-0002-6429-4461

Department of Family Medicine,

Kyung Hee University Medical Center,

23 Kyunghee dae-ro, Dongdaemun-

gu, Seoul 02447, Korea

Tel: +82-2-958-8691

Fax: +82-2-958-8699

E-mail: chunwon62@naver.com

Received: November 22, 2018

Accepted: December 10, 2018
Sarcopenia, a common clinical syndrome in older adults, is defined as decreased muscle mass, strength, and physical performance. Since sarcopenia is associated with the incidence of functional decline, falls, and even mortality in older adults, researchers and health care providers have been keen to accumulate clinical evidence to advocate the screening and prevention of sarcopenia progression in older adults. The factors that may accelerate the loss of muscle mass and function include chronic diseases, inactivity, and deficiency in appropriate nutritional support. Among these, nutritional support is considered an initial step to delay the progression of muscle wasting and improve physical performance in community-dwelling older adults. However, a nationwide study suggested that most Korean older adults do not consume sufficient dietary protein to maintain their muscle mass. Furthermore, considering age-associated anabolic resistance to dietary protein, higher protein intake should be emphasized in older adults than in younger people. To develop a dietary protein recommendation for older adults in Korea, we reviewed the relevant literature, including interventional studies from Korea. From these, we recommend that older adults consume at least $1.2 \mathrm{~g}$ of protein per $\mathrm{kg}$ of body weight per day (g/ $\mathrm{kg} /$ day) to delay the progression of muscle wasting. The amount we recommend $(1.2 \mathrm{~g} /$ $\mathrm{kg} /$ day) is $31.4 \%$ higher than the previously suggested recommended daily allowance (i.e., $0.91 \mathrm{~g} / \mathrm{kg} /$ day) for the general population of Korea. Also, evidence to date suggests that the combination of exercise and nutritional support may enhance the beneficial effects of protein intake in older adults in Korea. We found that the current studies are insufficient to build population-based guidelines for older adults, and we call for further researches in Korea. (Ann Geriatr Med Res 2018;22:167-175)

Key Words: Protein, Nutrition, Sarcopenia, Older people

\section{INTRODUCTION}

With an aging global population, developed countries are encountering care needs for unprecedented numbers of geriatric individuals. Among others, South Korea is one of countries with a rapidly aging population, largely due to rapid changes in social structure and advances in healthcare systems in the last 40 years. Indeed, a recent study suggested that the life expectancy of Koreans will be the longest among 35 developed countries in 2030. ${ }^{1)}$ 
Sarcopenia, defined as a state of decreased muscle mass and strength/performance that occurs with aging, ${ }^{2)}$ is one of the most common clinical syndromes observed in older adults. Indeed, prevalence of sarcopenia exceeds 15 percent in Korean community dwelling older people when assessed by algorithms from Asian Working Group of Sarcopenia. ${ }^{3,4)}$ Sarcopenia is associated with adverse health outcomes in older adults, increased incidence of disabilities, ${ }^{5)}$ increased risk of falls, ${ }^{6}$ vulnerabilities to various medical $^{7,8)}$ and surgical treatments, ${ }^{9)}$ lower quality of life, ${ }^{10)}$ and even increased risk of death. ${ }^{11,12)}$ With these possible serious adverse outcomes associated with sarcopenia, researchers and health care providers have been ardent to create clinical evidences to advocate screening and preventing progressions of sarcopenia in older adults. ${ }^{13-15)}$

Cumulating studies have discovered multiple pathophysiological factors and clinical conditions in sarcopenia that may be applicable for interventions. Among clinical conditions, chronic diseases, ${ }^{16)}$ inactivity, ${ }^{17)}$ frailty ${ }^{18)}$ and deficiency in appropriate nutritional support ${ }^{17)}$ have been associated with worsening muscle wasting. Researchers from academia and pharmaceutical industries have identified and targeted various molecular pathways to combat sarcopenia, including the myostatin/activin pathway, ${ }^{19,20)}$ androgen $^{21)}$ or other intranuclear receptor pathways, the mammalian target of rapamycinm (TOR) associated pathways, ${ }^{22)}$ and others. ${ }^{23)}$ However, nutritional support has been considered a low-hanging fruit or practical starting step to delay the progression of muscle wasting and improve physical performance in community-dwelling older adults, in terms of its clinical feasibility and lower cost compared to other kinds of interventions. ${ }^{24)}$

Since older adults are required to consume higher levels of essential amino acids (EAAs) to better preserve their muscles due to anabolic resistance, some scientists have suggested a higher target dietary protein intake in this population. ${ }^{25,26)}$ Following these movements and reflecting compelling needs for appropriate nutritional guidance for Korean older adults regarding sarcopenia, the SarcopeniaFrailty Study Group of the Korean Geriatric Society and the Korean Nutrition Society cooperated to provide this position paper on evidence-based recommendations for dietary protein intake to delay the progression of sarcopenia in older adults.

\section{THE CONSENSUS DEVELOPMENT PROCESS}

\section{Composition of the Consensus Development Committee}

The Korean Geriatric Society and the Korean Nutrition Society co-organized a committee for the development of a consensus on dietary protein intake to reduce the incidence of sarcopenia and prevent the progression of muscle loss in Korean older adults. The committee included Chang Won Won, Hee-Won Jung, Sun-Wook Kim, Il-Young Kim, Jae-Young Lim, Hyoung-Su Park, Wook Song, Hyung Joon Yoo, Hak-Chul Jang from the Sarcopenia-Frailty
Study Group of the Korean Geriatric Society and Kirang Kim, Yongsoon Park, Yoon Jung Park, Soo Jin Yang, and Hae-Jeung Lee from the Korean Nutrition society. The consensus was prepared in an interdisciplinary manner, and the committee included professionals from geriatric medicine, family medicine, rehabilitation medicine, exercise physiology, and nutritional science. The committee had 4 meetings from 2016 to 2017 to develop research questions and literature reviews.

\section{Working Process to Elicit Consensus}

This recommendation was predicated on evidence-based medicine. Primarily, we collected evidence on protein intake and muscle mass or physical performance from among Korean studies. Also, since evidence on the effect of protein supplementation in Korea is scarce, we conducted a literature review of the existing recommendations and guidelines for protein intake of older adults from Google Scholar, PubMed, EBSCO, and Web of Science using the keywords "sarcopenia AND protein," "sarcopenia AND protein AND guideline," and "sarcopenia AND nutrition." After finding key studies, we constructed our key questions to prepare our guideline to provide clinically meaningful guidance. Our key questions included (1) What is the clinically recommended protein intake for Korean older adults? (2) Is there clinical relevance in varying characteristics of protein? (3) Are there synergistic benefits of exercise on nutritional support? (4) How should we address older patients with acute or chronic diseases in terms of dietary protein intake? Is increasing dietary protein intake harmful in some patient populations?

\section{Completion of the Expert Consensus Guidelines}

We used a nominal group technique to produce consensus guidelines based on the agreed opinions from the committee members. First, preliminary ideas from the Korean Nutrition Society were presented, and we derived agreed opinions in group discussions. The committee prepared key ideas from the discussions and presented the resulting preliminary guidelines at the Korean Geriatric Society Autumn meeting on November 27, 2016, to gather opinions and requests from participants of the major academic society in Korea.

\section{CLINICALLY RECOMMENDED PROTEIN INTAKE IN KO- REAN OLDER ADULTS}

Summary: Based on the currently available evidence, we recommend a dietary protein intake of $>1.2 \mathrm{~g} / \mathrm{kg}$ and $>20 \mathrm{~g}$ EAAs per day in healthy older adults.

Historically, recommendations for dietary protein intake have been based on the estimated minimum amount required to maintain nitrogen balance in adults, without considering physiological and biochemical alterations in maintaining skeletal muscle mass in older adults. ${ }^{26)}$ In Ko- 
rea, the current estimated average requirement (EAR) and recommended daily allowance (RDA) for protein intake are $0.73 \mathrm{~g}$ protein per $\mathrm{kg}$ of body weight per day $(\mathrm{g} / \mathrm{kg} /$ day) and $0.91 \mathrm{~g} / \mathrm{kg} /$ day, respectively, for the general adult population. ${ }^{27)}$ Using these EAR and RDA values, Park ${ }^{28)}$ evaluated the status of dietary protein intake in older people aged 60 years or older using a 24-hour recall nutrition survey (NS) in the 6th Korea National Health and Nutrition Survey (KNHANES) from 2013 to 2014. In this study, the mean protein intakes were 1.03 and $0.90 \mathrm{~g} / \mathrm{kg} /$ day in men and women, respectively. In terms of the EAR, 30.8\% of the older men and $42.6 \%$ of the older women had insufficient protein intake. Based on the RDA, 47.9\% of men and $60.1 \%$ of women had insufficient protein intake.

However, accumulating evidence has indicated that the RDA of dietary protein for the general adult population is insufficient to protect the muscle mass from catabolism in older adults. ${ }^{29,30)}$ The RDA assumes that it is enough to meet the dietary requirements of most of the healthy adult population. In older adults, however, anabolic resistance exists as a result of the diminished response of muscle protein synthesis (MPS) to EAAs. ${ }^{31)}$ For example, in a study that administered a small bolus of EAAs, the amount of muscle protein accretion (protein synthesis-protein breakdown) measured by stable isotope tracers was diminished in older adults compared to that in their younger counterparts. ${ }^{32)}$ Similarly, when an EAA-fortified meal was provided, a higher proportion of leucine, which is known to stimulate the mTOR axis, was required to stimulate MPS in older but not younger adults. ${ }^{33)}$

Clinically, studies have also shown the possible beneficial effects of an increased dietary protein intake on muscle mass and functional status in older adults. ${ }^{34,35)}$ In observational studies, an analysis from the Health, Aging, and Body Composition study showed that the level of calorie-adjusted dietary protein intake (estimated by food frequency questionnaire) was associated with 3-year longitudinal changes in lean body mass. ${ }^{34)}$ In this study population, the mean daily protein intake was $0.9 \mathrm{~g} / \mathrm{kg}$ per day and participants in the highest quintile $(1.2 \pm 0.4 \mathrm{~g} / \mathrm{kg}$ per day) lost $43 \%$ less lean mass compared to those in the lowest quintile $(0.8 \pm 0.3 \mathrm{~g} / \mathrm{kg}$ per day). Also, in an observational study performed by the Women's Health Initiative, ${ }^{36)}$ a 20\% higher baseline calibrated protein intake estimated from food frequency questionnaires was associated with a 32\% (95 confidence interval [CI], 23\%-50\%) decreased risk of the frailty phenotype defined by Fried et al. ${ }^{37)}$ A crosssectional study from the Nutrition and Health Survey in Taiwan $^{38)}$ showed that a dietary pattern of increased consumption of protein-rich foods such as shellfish and milk was associated with a reduced prevalence of frailty, better grip strength, and higher physical activity.

Based on these observations, many interventional studies were conducted to assess the beneficial effects of protein supplementation on the muscle mass or physical performance of older people. In Korea, a community-based randomized controlled trial showed that providing protein energy supplements (additional $400 \mathrm{kcal}$ of energy and 25 $\mathrm{g}$ of protein including $9.4 \mathrm{~g}$ of EAAs per day) to socioeconomically-deprived older adults (income level $<120 \%$ of the national absolute poverty line) for 12 weeks resulted in better short physical performance battery score (SPPB), usual gait speed, and timed up-and-go test at the study endpoint in the intervention group compared to those in the control group. ${ }^{39)}$ In a recent multicomponent interventional study from the Aging Study of Pyeongchang Rural Area (ASPRA), ${ }^{40)}$ a combined program of a 24-week schedule including 60-minute group exercise, nutritional support of $26 \mathrm{~g}$ of protein with $11.26 \mathrm{~g}$ EAAs per day, psychiatric intervention for depression, and geriatric intervention to discontinue potentially inappropriate medicines was associated with a 3.2-point improvement in SPPB score (from a baseline score of 7.4) at the end of the intervention period. The beneficial effect was maintained for 6 months after the end of the intervention. In the ASPRA study, although it is impossible to dissect the sole effect of protein supplementation in the functional improvements, one notable point is that the amount of protein supplement was designed to fill the gap between the current average protein intake of Korean older adults and the recommended $1.0-1.2 \mathrm{~g} / \mathrm{kg} /$ day of the recent consensus. Another recent interventional study from Korea ${ }^{41)}$ showed that increased dietary protein supplementation was associated with higher muscle mass and better gait speed after a 12-week intervention; the researchers observed the greatest benefit with a targeted protein intake of $1.5 \mathrm{~g} / \mathrm{kg} /$ day. A recent placebo controlled randomized nutritional intervention study using calorie-adjusted protein (with vitamin D and vitamin E) supplementation ${ }^{42)}$ for 6 months in sarcopenic older adults in China showed better relative skeletal muscle mass index, higher handgrip strength, better quality of life index, and increased serum insulin-like growth factor-1 level in the intervention group compared to those in the placebo control group. The recent PRO$\mathrm{VIDE}^{24)}$ study used active supplementation of $40 \mathrm{~g}$ whey protein and $6 \mathrm{~g}$ total leucine per day with a control consisting of an isocaloric control product in older adults with SPPB scores ranging from 4 to 9 . In that study, the chair stand test results improved significantly by 1.01 seconds and appendicular muscle mass increased by $0.17 \mathrm{~kg}$ in the active supplement group, compared to those in the isocaloric control group.

Based on this collected evidence and the consensus, ${ }^{25,29,30,43,44)}$ the panel from the Korean Geriatric Society and the Korean Nutrition Society suggest a dietary protein intake of $>1.2 \mathrm{~g} / \mathrm{kg} /$ day and an EAA intake of $>20 \mathrm{~g} /$ day in community-dwelling older adults. Considering this evidence and the high rate of undernourished individuals, many Korean older adults consume insufficient amounts of dietary proteins ${ }^{28)}$ in terms of both RDA and the recently proposed increased target of $>1.2 \mathrm{~g} / \mathrm{kg} /$ day. ${ }^{43)}$ Therefore, we emphasize the unmet and evident needs of increased 
dietary protein intake in the general older Korean population.

\section{IS THERE CLINICAL RELEVANCE FOR VARIOUS PRO- TEIN CHARACTERISTICS?}

Summary: Protein quality and source may be considered when providing recommendations for dietary protein intake in older people. Leucine or BCAA and, $\beta-H M B$ enrichment may be beneficial, although the clinical evidence remains insufficient. Fast protein (for example, whey protein) may be beneficial compared to slow protein (for example, casein protein), and protein of animal origin may be better than plant based protein in promoting muscle mass.

\section{Leucine, Branched-Chain Amino Acids, and $\beta$-HMB}

Studies have suggested that varying compositions of amino acids and parameters in terms of absorbance in dietary protein may affect anabolic characteristics. ${ }^{45,46)}$ Previous mechanism studies have suggested that leucine, a branched-chain amino acid (BCAAs: leucine, isoleucine, and valine), might be the key to stimulate MPS via targeting of the mTOR system; this mechanistic hypothesis has been validated in human studies. ${ }^{47,48)}$ However, the clinically meaningful benefits of BCAA supplementation remains elusive, with controversial effects of BCAAs or leucine supplementation in terms of a beneficial net protein balance. ${ }^{49,50)}$ In a study that administered a $20 \mathrm{~g}$ bolus of labeled casein protein with or without $2.5 \mathrm{~g}$ of crystalline leucine, the postprandial MPS was higher for leucine co-administration in older men (mean age, 74 years). ${ }^{51)}$ However, in a study that administered long-term leucine supplementation to older men (mean age, 71 years), 2.5 $\mathrm{g}$ of leucine provided with each meal for 3 months was not associated with either increased muscle mass or leg strength at the end of the study period. ${ }^{52)}$

$\beta$-hydroxy- $\beta$-methylbutyrate ( $\beta$-HMB), a metabolite of leucine endogenously produced in myocytes that simulates MPS through various mechanisms (MAPK/ERK, PI3K/Akt, and mTOR pathways), has been a recent research interest with respect to its possible beneficial effects in preserving muscle mass and strength in older adults. ${ }^{22,53,54)}$ In a small study of older adults with SPPB scores of 9 or higher, daily supplementation with $3 \mathrm{~g} \beta$-HMB was associated with less lean mass loss following a 10-day bed rest, ${ }^{55)}$ although without significant functional benefits. In a recent systematic review, $\beta$-HMB was associated with improvement in lean mass, albeit without significant efficacy in muscle function. ${ }^{56)}$ Ongoing clinical studies to assess the effects of $\beta$-HMB will provide further evidence of its potentially beneficial role in muscle mass and physical performance in older people (NCT02679742, NCT02043171).

\section{Absorption Characteristics and Intake Patterns of Pro- teins}

Researchers have studied the effects of the differential absorption properties of dietary proteins on muscle mass regulation. In older adults, postprandial aminoacidemia and leucine flux and oxidation were greater for whey protein (so-called 'fast' protein) meals compared to those for casein protein (so-called 'slow' protein) meals. ${ }^{57,58)}$ Clinically in healthy older adults, Walrand et al. ${ }^{59)}$ assessed a 10-day protein supplementation, reporting that soluble milk proteins ('fast' protein) were better than casein protein ('slow' proteins) in terms of overcoming anabolic resistance associated with aging. Considering this evidence, 'fast' protein consumption in older adults may help to better preserve muscle mass.

Recently, researchers have hypothesized that evenly spreading the total daily protein intake throughout the day would benefit the preserving of muscle health in older adults. This hypothesis has been based on the observation that the majority of protein intake occurred in dinner meals. ${ }^{60)}$ However, a study on protein feeding patterns in healthy young women ${ }^{61)}$ showed no differences in nitrogen balance and whole body protein turnover between pulse (protein intake mainly in 1 meal) and spread (dividing daily protein intake over 4 meals) intake patterns in 2-week experimental periods. A randomized clinical trial performed in 20 healthy older adults (52 to 75 years of age) in an acute period (4 days) of protein meal intake revealed that the quantity but not the pattern of dietary protein intake determined the net protein accretion. ${ }^{62}$ Similarly, a more recent randomized clinical study ${ }^{60)}$ showed that 8 weeks of even or uneven intake distributions of $1.1 \mathrm{~g} / \mathrm{kg} /$ day of protein resulted in no differences in muscle anabolic responses and strength and function in healthy older people. Based on this evidence, we recommend that older people increase their daily protein intake and that ancillary strategies to modify protein absorption characteristics, and dietary patterns might be considered.

\section{Protein Sources}

Milk- and soy-based proteins have been widely used for supplementation. Although both have capped scores of 100 in terms of protein digestibility-corrected amino acid score (PDCAAS), there have been controversies regarding the varying effects on amino acid accretion in skeletal muscle according to the sources of dietary protein. ${ }^{63-65)}$ In an acute study of healthy younger people that compared amino acid incorporation between soy- and milk-protein supplements after resistance exercise, the net amino acid balance and protein fractional synthesis rate in muscles were higher for milk consumption than that for soy consumption. ${ }^{66)}$ In a recent study using stable isotope amino acid tracers to measure whole body protein kinetics in older people, an egg-based isocaloric and isonitrogenous breakfast meal was associated with less protein breakdown 
and better net protein balance compared to those of a cereal-based control breakfast meal. ${ }^{67)}$ The results of these studies support the hypothesis that protein source and quality may affect net protein accretion.

\section{ARE THERE SYNERGISTIC BENEFITS OF EXERCISE AND NUTRITION?}

Summary: Evidence has shown that combining timely exercise and protein intake may synergistically stimulate MPS, leading to improved muscle mass and strength in older people.

MPS have been shown to increase up to 48 hours after resistance exercise in healthy adults. ${ }^{68)}$ However, net protein balance, although improved compared to that in the basal nonexercise period, was still negative, due to muscle protein breakdown (MPB) exceeding MPS throughout the entire experimental time period ${ }^{68)} \mathrm{A}$ subsequent physiological study showed that combining resistance exercise with 6 g EAA drink versus a flavored placebo drink ${ }^{69)}$ consumed 1 hour and 3 hours after exercise showed that EAAs with carbohydrates stimulated MPS but had no effect on MPB when compared to those for the placebo drink.

In clinical intervention studies, Tieland et al. ${ }^{70)}$ used a progressive resistance exercise program for 6 months with supplementary protein (15 g twice daily) or placebo in prefrail/frail older people (mean baseline body mass index [BMI] of $28.5 \mathrm{~kg} / \mathrm{m}^{2}$ ). In this study, lean mass gain was observed only in the protein supplementation group, although there was no statistically significant treatment (protein supplement) effect on physical performance. Another study by Chale et al. ${ }^{71)}$ compared the effects of whey protein concentrate to that of an isocaloric control on muscle mass and physical performance when combined with a progressive high-intensity resistance exercise in mobility-limited older adults (mean baseline BMI of 27.0 $\mathrm{kg} / \mathrm{m}^{2}$ ). In this study, the total body lean mass increased by $1.3 \%$ in the whey protein group and by $0.6 \%$ in the control group, although the difference was not statistically significant. There was no statistically significant difference in before-after changes between groups in terms of physical performance.

Kim et al. ${ }^{72)}$ assessed the differential effects of exercise and amino acid supplementation on muscle strength in a $2 \times 2$ randomized controlled trial in older, sarcopenic Japanese women (mean baseline BMI of $18.7 \mathrm{~kg} / \mathrm{m}^{2}$ ). In this 3-month study, only the combined exercise and amino acid group had significantly better knee extension strength than that of the health education group in post hoc analysis between 4 groups, suggesting the possible synergistic effects of amino acid supplementation and exercise. In contrast to 2 previous studies from western countries, the lower baseline BMI in this Asian study may be attributable to the synergistic role of amino acid supplementation and exercise. Similarly, in a Korean multicomponent study incorporating exercise, nutrition, and geriatric assessment in rural community-dwelling older people with social vulnerability, ${ }^{40)}$ lower BMI $\left(<27 \mathrm{~kg} / \mathrm{m}^{2}\right)$ was associated with a better response to the intervention, suggesting that the beneficial effect of nutritional support would be greater in people with protein nutrition deficits when combined with exercise. $^{35)}$

With varying results from individual studies, Cermak et al. ${ }^{73)}$ combined 22 randomized controlled trials including 680 young and older adults to assess the efficacy of protein supplementation in augmenting the effects of resistance exercise. The pooled analysis revealed that protein supplementation was associated with improvements in fatfree mass and leg press strength when compared to those for a placebo after resistance exercise in both young and older adults. Based on this evidence, combining protein intake with appropriate exercise may synergistically improve muscle mass and strength in older adults.

\section{HOW TO DEAL WITH OLDER PATIENTS WITH ACUTE OR CHRONIC DISEASES?}

Summary: For geriatric patients with acute or chronic diseases, tailored approaches for specific patients are recommended.

\section{Acute IIIness and Hospitalization}

Nutritional support for older adults with acute illness and hospitalization should be tailored to their specific clinical situations. Hospitalized situations often make appropriate and sufficient protein intake difficult. However, studies suggest that sufficient protein and calorie supplementation may be beneficial in cases of acute illness with catabolic status. A study in Korea on nutritional status based on the Geriatric Nutritional Risk index showed that a poor baseline nutritional status in hospitalized patients was associated with worse 28-day mortality. ${ }^{74)}$ However, to our knowledge, no study in Korea has assessed protein intake and clinical outcomes in acute or critical illness.

\section{Chronic Kidney Disease}

In older adults with class 1 to 2 chronic kidney disease (CKD, estimated glomerular filtration rate [eGFR] $>60 \mathrm{~mL} /$ $\min / 1.73 \mathrm{~m}^{2}$ ), a protein intake similar to that of healthy older people appears to be safe, with no notable literaturebased evidence to suggest protein restriction in this population. The 2012 Kidney Disease Improving Global Outcomes (KDIGO) guideline indicated that there appears to be no benefit in restricting protein intake to less than 0.8 $\mathrm{g} / \mathrm{kg} /$ day based on clinical trials. ${ }^{75}$ However, the KDIGO suggested to avoid high protein intake ( $>1.3 \mathrm{~g} / \mathrm{kg}$ per day) in adults with CKD at risk of progression. The PROT-AGE group suggested that a protein intake of $>0.8 \mathrm{~g} / \mathrm{kg}$ per day is safe with GFR monitoring in CKD patients with an eGFR of $30-60 \mathrm{~mL} / \mathrm{min} / 1.73 \mathrm{~m}^{2,25)}$ and that protein intake should 
Table 1. Summary of the recommendations from the joint committee of the Sarcopenia-Frailty Study Group of the Korean Geriatric Society and the Korean Nutrition Society

Summary of the recommendations

1. What is the clinically recommended protein intake for Korean older adults?

Based on the currently available evidence, we recommend a dietary protein intake of $>1.2 \mathrm{~g} / \mathrm{kg}$ and $>20$ g essential amino acids per day in healthy older adults.

2. Is there clinical relevance in varying the protein characteristics?

Protein quality and source may be considered when providing recommendations for dietary protein intake in older people. Leucine or BCAAs and $\beta$-HMB enrichment may be beneficial, although the clinical evidence is insufficient. Fast protein (for example, whey protein) may be beneficial compared to slow protein (for example, casein protein), and protein of animal origin may be better than plant-based protein in promoting muscle mass.

3. Are there synergistic benefits of exercise on nutritional support?

Evidence indicates that the combination of timely exercises with protein intake may synergistically stimulate muscle protein synthesis, leading to improved muscle mass and strength in older people.

4. How to address older patients with acute or chronic diseases in terms of dietary protein intake?

For geriatric patients with acute or chronic diseases, tailored approaches for specific patients are recommended.

BCAA, branched chain amino acids; $\beta$-HMB, $\beta$-hydroxy- $\beta$-methylbutyrate.

be limited to $0.8 \mathrm{~g} / \mathrm{kg}$ per day in patients with an eGFR $<30 \mathrm{~mL} / \mathrm{min} / 1.73 \mathrm{~m}^{2}$.

On the other hand, patients undergoing hemodialysis or peritoneal dialysis do not have to prevent progression of CKD, with ongoing catabolic pressure by dialysis. Therefore, in these patients, experts recommend that the protein intake should be maintained at $>1.8 \mathrm{~g} / \mathrm{kg}$ per day. ${ }^{25)}$ Since physical frailty is common and associated with adverse outcomes in patients with $\mathrm{CKD},{ }^{76-78)}$ more studies on this issue in Korea are required to develop population-based recommendations.

\section{Liver Cirrhosis}

The prevalence and mortality due to liver cirrhosis are higher in Korea compared to those in western countries. ${ }^{79)}$ Therefore, the issue of dietary protein intake should be addressed in Korea, since liver cirrhosis is a well-known clinical condition for which either access or insufficient intake may be harmful for clinical outcomes of the patients.

Liver cirrhosis is an intriguing clinical condition in older adults. On the one hand, protein intake should be restricted in patients with advanced disease to prevent hepatic encephalopathy. ${ }^{80)}$ On the other hand, malnutrition is one of the most frequent clinical problems in liver cirrhosis and sarcopenia is directly associated with poor clinical outcomes in cirrhotic patients. ${ }^{80,81)}$ With these clinical issues, the Japan Society of Hepatology recently published the first guideline for sarcopenia in patients with liver diseases. ${ }^{82)}$ Regarding protein support in this population, the few studies have focused mostly on BCAAs ${ }^{83-85)}$ rather than on total protein intake. However, the authors did not find any clinical research on protein intake in older cirrhotic patients in Korea.

\section{CONCLUDING REMARKS AND SUGGESTIONS FOR FURTHER RESEARCH}

This joint committee of Sarcopenia-Frailty Study group of the Korean Geriatric Society and the Korean Nutrition Society made evidence-based recommendations regarding dietary protein intake to prevent or delay sarcopenia in Korean older adults, as summarized in Table 1. We noted that older people are consuming suboptimal amounts of dietary protein considering the protein requirements to support muscle mass and performance in Korea. Although developed countries have been accumulating researchbased evidence to guide dietary intake in both healthy older people and people with comorbidities, we noted that the research is insufficient in developing evidence-based guidelines for protein intake in the Korean older population. We posit that there should be more well-designed, prospective studies on protein intake in older people of Korea in terms of (1) the amount of daily protein intake; (2) the effects of varying proteins characteristics, amino acids, or amino acid analogues; (3) the synergistic benefits of combining resistance exercise and protein supplements; and (4) the effect of dietary protein intake on various clinical conditions. Based on these studies to be conducted in the future, we have to promote public awareness of the importance of sufficient daily protein intake to prevent or at least delay the development and progression of sarcopenia and the frailty spectrum.

\section{CONFLICTS OF INTEREST DISCLOSURES}

The researchers claim no conflicts of interest.

\section{REFERENCES}

1. Kontis V, Bennett JE, Mathers CD, Li G, Foreman K, Ezzati M. Future life expectancy in 35 industrialised countries: projections with a Bayesian model ensemble. Lancet 2017;389:1323-35.

2. Cruz-Jentoft AJ, Baeyens JP, Bauer JM, Boirie Y, Cederholm T, Landi F, et al. Sarcopenia: European consensus on definition and diagnosis: Report of the European Working Group on Sarcopenia in Older People. Age Ageing 2010;39:412-23.

3. Chen LK, Liu LK, Woo J, Assantachai P, Auyeung TW, Bahyah KS, 
et al. Sarcopenia in Asia: consensus report of the Asian Working Group for Sarcopenia. J Am Med Dir Assoc 2014;15:95-101.

4. Jang IY, Jung HW, Lee CK, Yu SS, Lee YS, Lee E. Comparisons of predictive values of sarcopenia with different muscle mass indices in Korean rural older adults: a longitudinal analysis of the Aging Study of PyeongChang Rural Area. Clin Interv Aging 2018;13:919.

5. Cesari M. Physical frailty and sarcopenia: development of a framework for supporting interventions against incident mobility disability. Ann Geriatr Med Res 2017;21:42-8.

6. Landi F, Liperoti R, Russo A, Giovannini S, Tosato M, Capoluongo E, et al. Sarcopenia as a risk factor for falls in elderly individuals: results from the ilSIRENTE study. Clin Nutr 2012;31:652-8.

7. Jung HW, Kim JW, Kim JY, Kim SW, Yang HK, Lee JW, et al. Effect of muscle mass on toxicity and survival in patients with colon cancer undergoing adjuvant chemotherapy. Support Care Cancer 2015;23:687-94.

8. Prado CM, Baracos VE, McCargar LJ, Reiman T, Mourtzakis M, Tonkin K, et al. Sarcopenia as a determinant of chemotherapy toxicity and time to tumor progression in metastatic breast cancer patients receiving capecitabine treatment. Clin Cancer Res 2009;15:2920-6.

9. Englesbe MJ, Patel SP, He K, Lynch RJ, Schaubel DE, Harbaugh C, et al. Sarcopenia and mortality after liver transplantation. J Am Coll Surg 2010;211:271-8.

10. Verlaan S, Aspray TJ, Bauer JM, Cederholm T, Hemsworth J, Hill TR, et al. Nutritional status, body composition, and quality of life in community-dwelling sarcopenic and non-sarcopenic older adults: A case-control study. Clin Nutr 2017;36:267-74.

11. Jung HW, Kim SW, Chin HJ, Kim CH, Kim KI. Skeletal muscle mass as a predictor of mortality in the elderly population. Korean J Med 2013;85:167-73.

12. Kim JH, Lim S, Choi SH, Kim KM, Yoon JW, Kim KW, et al. Sarcopenia: an independent predictor of mortality in communitydwelling older Korean men. J Gerontol A Biol Sci Med Sci 2014;69:1244-52.

13. Cao L, Morley JE. Sarcopenia is recognized as an independent condition by an International Classification of Disease, Tenth Revision, Clinical Modification (ICD-10-CM) code. J Am Med Dir Assoc 2016;17:675-7.

14. Jang HC. How to diagnose sarcopenia in Korean older adults? Ann Geriatr Med Res 2018;22:73-9.

15. Park HM. Current status of sarcopenia in Korea: a focus on Korean geripausal women. Ann Geriatr Med Res 2018;22:52-61.

16. Cohen S, Nathan JA, Goldberg AL. Muscle wasting in disease: molecular mechanisms and promising therapies. Nat Rev Drug Discov 2015;14:58-74.

17. Thomas DR. Loss of skeletal muscle mass in aging: examining the relationship of starvation, sarcopenia and cachexia. Clin Nutr 2007;26:389-99.

18. Jung HW, Kim SW, Lim JY, Kim KW, Jang HC, Kim CH, et al. Frailty status can predict further lean body mass decline in older adults. J Am Geriatr Soc 2014;62:2110-7.

19. Rooks D, Praestgaard J, Hariry S, Laurent D, Petricoul O, Perry RG, et al. Treatment of sarcopenia with bimagrumab: results from a phase II, randomized, controlled, proof-of-concept study. J Am
Geriatr Soc 2017;65:1988-95.

20. Becker C, Lord SR, Studenski SA, Warden SJ, Fielding RA, Recknor CP, et al. Myostatin antibody (LY2495655) in older weak fallers: a proof-of-concept, randomised, phase 2 trial. Lancet Diabetes Endocrinol 2015;3:948-57.

21. Papanicolaou DA, Ather SN, Zhu H, Zhou Y, Lutkiewicz J, Scott $\mathrm{BB}$, et al. A phase IIA randomized, placebo-controlled clinical trial to study the efficacy and safety of the selective androgen receptor modulator (SARM), MK-0773 in female participants with sarcopenia. J Nutr Health Aging 2013;17:533-43.

22. Cruz-Jentoft AJ. Beta-hydroxy-beta-methyl butyrate (HMB): From experimental data to clinical evidence in sarcopenia. Curr Protein Pept Sci 2018;19:668-72.

23. Benoit B, Meugnier E, Castelli M, Chanon S, Vieille-Marchiset A, Durand C, et al. Fibroblast growth factor 19 regulates skeletal muscle mass and ameliorates muscle wasting in mice. Nat Med 2017;23:990-6.

24. Bauer JM, Verlaan S, Bautmans I, Brandt K, Donini LM, Maggio $\mathrm{M}$, et al. Effects of a vitamin D and leucine-enriched whey protein nutritional supplement on measures of sarcopenia in older adults, the PROVIDE study: a randomized, double-blind, placebocontrolled trial. J Am Med Dir Assoc 2015;16:740-7.

25. Bauer J, Biolo G, Cederholm T, Cesari M, Cruz-Jentoft AJ, Morley JE, et al. Evidence-based recommendations for optimal dietary protein intake in older people: a position paper from the PROTAGE Study Group. J Am Med Dir Assoc 2013;14:542-59.

26. Baum JI, Kim IY, Wolfe RR. Protein consumption and the elderly: what is the optimal level of intake? Nutrients 2016 Jun 8;8(6). pii: E359. https://doi.org/10.3390/nu8060359.

27. Ministry of Health and Welfare. Dietary reference intakes for Koreans. Sejong (Korea): Ministry of Health and Welfare; 2015.

28. Park HA. Adequacy of Protein Intake among Korean Elderly: An Analysis of the 2013-2014 Korea National Health and Nutrition Examination Survey Data. Korean J Fam Med 2018;39:130-4.

29. Volpi E, Campbell WW, Dwyer JT, Johnson MA, Jensen GL, Morley JE, et al. Is the optimal level of protein intake for older adults greater than the recommended dietary allowance? J Gerontol A Biol Sci Med Sci 2013;68:677-81.

30. Morais JA, Chevalier S, Gougeon R. Protein turnover and requirements in the healthy and frail elderly. J Nutr Health Aging 2006;10:272-83.

31. Breen L, Phillips SM. Skeletal muscle protein metabolism in the elderly: Interventions to counteract the 'anabolic resistance' of ageing. Nutr Metab (Lond) 2011;8:68.

32. Katsanos CS, Kobayashi H, Sheffield-Moore M, Aarsland A, Wolfe RR. Aging is associated with diminished accretion of muscle proteins after the ingestion of a small bolus of essential amino acids. Am J Clin Nutr 2005;82:1065-73.

33. Katsanos CS, Kobayashi H, Sheffield-Moore M, Aarsland A, Wolfe RR. A high proportion of leucine is required for optimal stimulation of the rate of muscle protein synthesis by essential amino acids in the elderly. Am J Physiol Endocrinol Metab 2006;291:E3817.

34. Houston DK, Nicklas BJ, Ding J, Harris TB, Tylavsky FA, Newman $\mathrm{AB}$, et al. Dietary protein intake is associated with lean mass change in older, community-dwelling adults: the Health, Ag- 
ing, and Body Composition (Health $\mathrm{ABC}$ ) Study. Am J Clin Nutr 2008;87:150-5.

35. Layman DK, Evans E, Baum JI, Seyler J, Erickson DJ, Boileau RA. Dietary protein and exercise have additive effects on body composition during weight loss in adult women. J Nutr 2005;135:190310.

36. Beasley JM, LaCroix AZ, Neuhouser ML, Huang Y, Tinker L, Woods N, et al. Protein intake and incident frailty in the Women's Health Initiative observational study. J Am Geriatr Soc 2010;58:1063-71.

37. Fried LP, Tangen CM, Walston J, Newman AB, Hirsch C, Gottdiener J, et al. Frailty in older adults: evidence for a phenotype. J Gerontol A Biol Sci Med Sci 2001;56:M146-56.

38. Lo YL, Hsieh YT, Hsu LL, Chuang SY, Chang HY, Hsu CC, et al. Dietary pattern associated with frailty: results from Nutrition and Health Survey in Taiwan. J Am Geriatr Soc 2017;65:2009-15.

39. Kim CO, Lee KR. Preventive effect of protein-energy supplementation on the functional decline of frail older adults with low socioeconomic status: a community-based randomized controlled study. J Gerontol A Biol Sci Med Sci 2013;68:309-16.

40. Jang IY, Jung HW, Park H, Lee CK, Yu SS, Lee YS, et al. A multicomponent frailty intervention for socioeconomically vulnerable older adults: a designed-delay study. Clin Interv Aging 2018;13:1799-814

41. Park Y, Choi JE, Hwang HS. Protein supplementation improved muscle mass and physical performance in the undernourished prefrail and frail elderly: a randomized, double-blind, placebo controlled trial. Am J Clin Nutr 2018;108:1026-33.

42. Bo Y, Liu C, Ji Z, Yang R, An Q, Zhang X, et al. A high whey protein, vitamin $\mathrm{D}$ and $\mathrm{E}$ supplement preserves muscle mass, strength, and quality of life in sarcopenic older adults: A double-blind randomized controlled trial. Clin Nut. 2018 Jan 9 [Epub]. pii: S02615614(18)30007-4. https://doi.org/0.1016/j.clnu.2017.12.020.

43. Paddon-Jones D, Rasmussen BB. Dietary protein recommendations and the prevention of sarcopenia. Curr Opin Clin Nutr Metab Care 2009;12:86-90.

44. Deutz NE, Bauer JM, Barazzoni R, Biolo G, Boirie Y, Bosy-Westphal A, et al. Protein intake and exercise for optimal muscle function with aging: recommendations from the ESPEN Expert Group. Clin Nutr 2014;33:929-36.

45. Bauer JM, Diekmann R. Protein supplementation with aging. Curr Opin Clin Nutr Metab Care 2015;18:24-31.

46. Volpi E, Kobayashi H, Sheffield-Moore M, Mittendorfer B, Wolfe RR. Essential amino acids are primarily responsible for the amino acid stimulation of muscle protein anabolism in healthy elderly adults. Am J Clin Nutr 2003;78:250-8.

47. Dreyer HC, Drummond MJ, Pennings B, Fujita S, Glynn EL, Chinkes DL, et al. Leucine-enriched essential amino acid and carbohydrate ingestion following resistance exercise enhances mTOR signaling and protein synthesis in human muscle. Am J Physiol Endocrinol Metab 2008;294:E392-400.

48. Norton LE, Layman DK. Leucine regulates translation initiation of protein synthesis in skeletal muscle after exercise. J Nutr 2006;136:533S-7S.

49. Wolfe RR. Branched-chain amino acids and muscle protein synthesis in humans: myth or reality? J Int Soc Sports Nutr
2017;14:30.

50. Casperson SL, Sheffield-Moore M, Hewlings SJ, Paddon-Jones D. Leucine supplementation chronically improves muscle protein synthesis in older adults consuming the RDA for protein. Clin Nutr 2012;31:512-9.

51. Wall BT, Hamer HM, de Lange A, Kiskini A, Groen BB, Senden $\mathrm{JM}$, et al. Leucine co-ingestion improves post-prandial muscle protein accretion in elderly men. Clin Nutr 2013;32:412-9.

52. Verhoeven S, Vanschoonbeek K, Verdijk LB, Koopman R, Wodzig WK, Dendale P, et al. Long-term leucine supplementation does not increase muscle mass or strength in healthy elderly men. Am J Clin Nutr 2009;89:1468-75.

53. Eley HL, Russell ST, Baxter JH, Mukerji P, Tisdale MJ. Signaling pathways initiated by beta-hydroxy-beta-methylbutyrate to attenuate the depression of protein synthesis in skeletal muscle in response to cachectic stimuli. Am J Physiol Endocrinol Metab 2007;293:E923-31.

54. Kornasio R, Riederer I, Butler-Browne G, Mouly V, Uni Z, Halevy 0. Beta-hydroxy-beta-methylbutyrate (HMB) stimulates myogenic cell proliferation, differentiation and survival via the MAPK/ERK and PI3K/Akt pathways. Biochim Biophys Acta 2009;1793:75563.

55. Deutz NE, Pereira SL, Hays NP, Oliver JS, Edens NK, Evans CM, et al. Effect of $\beta$-hydroxy- $\beta$-methylbutyrate (HMB) on lean body mass during 10 days of bed rest in older adults. Clin Nutr 2013;32:704-12.

56. Wu H, Xia Y, Jiang J, Du H, Guo X, Liu X, et al. Effect of betahydroxy-beta-methylbutyrate supplementation on muscle loss in older adults: a systematic review and meta-analysis. Arch Gerontol Geriatr 2015;61:168-75.

57. Dangin M, Boirie Y, Garcia-Rodenas C, Gachon P, Fauquant J, Callier $\mathrm{P}$, et al. The digestion rate of protein is an independent regulating factor of postprandial protein retention. Am J Physiol Endocrinol Metab 2001;280:E340-8.

58. Dangin M, Guillet C, Garcia-Rodenas C, Gachon P, Bouteloup-Demange $\mathrm{C}$, Reiffers-Magnani $\mathrm{K}$, et al. The rate of protein digestion affects protein gain differently during aging in humans. J Physiol 2003;549(Pt 2):635-44.

59. Walrand S, Gryson C, Salles J, Giraudet C, Migné C, Bonhomme $\mathrm{C}$, et al. Fast-digestive protein supplement for ten days overcomes muscle anabolic resistance in healthy elderly men. Clin Nutr 2016;35:660-8.

60. Kim IY, Schutzler S, Schrader AM, Spencer HJ, Azhar G, Wolfe $\mathrm{RR}$, et al. Protein intake distribution pattern does not affect anabolic response, lean body mass, muscle strength or function over 8 weeks in older adults: a randomized-controlled trial. Clin Nutr 2018;37:488-93.

61. Arnal MA, Mosoni L, Boirie Y, Houlier ML, Morin L, Verdier E, et al. Protein feeding pattern does not affect protein retention in young women.J Nutr 2000;130:1700-4.

62. Kim IY, Schutzler S, Schrader A, Spencer H, Kortebein P, Deutz NE, et al. Quantity of dietary protein intake, but not pattern of intake, affects net protein balance primarily through differences in protein synthesis in older adults. Am J Physiol Endocrinol Metab 2015;308:E21-8.

63. Millward DJ, Layman DK, Tomé D, Schaafsma G. Protein qual- 
ity assessment: impact of expanding understanding of protein and amino acid needs for optimal health. Am J Clin Nutr 2008;87:1576S-1581S.

64. Schaafsma G. The protein digestibility-corrected amino acid score. J Nutr 2000;130:1865S-1867S.

65. Phillips SM, Tang JE, Moore DR. The role of milk- and soybased protein in support of muscle protein synthesis and muscle protein accretion in young and elderly persons. J Am Coll Nutr 2009;28:343-54.

66. Wilkinson SB, Tarnopolsky MA, Macdonald MJ, Macdonald JR, Armstrong D, Phillips SM. Consumption of fluid skim milk promotes greater muscle protein accretion after resistance exercise than does consumption of an isonitrogenous and isoenergetic soyprotein beverage. Am J Clin Nutr 2007;85:1031-40.

67. Kim IY, Shin YA, Schutzler SE, Azhar G, Wolfe RR, Ferrando AA. Quality of meal protein determines anabolic response in older adults. Clin Nutr 2018;37(6 Pt A):2076-83.

68. Phillips SM, Tipton KD, Aarsland A, Wolf SE, Wolfe RR. Mixed muscle protein synthesis and breakdown after resistance exercise in humans. Am J Physiol 1997;273(1 Pt 1):E99-107.

69. Rasmussen BB, Tipton KD, Miller SL, Wolf SE, Wolfe RR. An oral essential amino acid-carbohydrate supplement enhances muscle protein anabolism after resistance exercise. J Appl Physiol (1985) 2000;88:386-92.

70. Tieland M, Dirks ML, van der Zwaluw N, Verdijk LB, van de Rest O, de Groot LC, et al. Protein supplementation increases muscle mass gain during prolonged resistance-type exercise training in frail elderly people: a randomized, double-blind, placebo-controlled trial. J Am Med Dir Assoc 2012;13:713-9.

71. Chalé A, Cloutier GJ, Hau C, Phillips EM, Dallal GE, Fielding RA. Efficacy of whey protein supplementation on resistance exerciseinduced changes in lean mass, muscle strength, and physical function in mobility-limited older adults. J Gerontol A Biol Sci Med Sci 2013;68:682-90.

72. Kim HK, Suzuki T, Saito K, Yoshida H, Kobayashi H, Kato H, et al. Effects of exercise and amino acid supplementation on body composition and physical function in community-dwelling elderly Japanese sarcopenic women: a randomized controlled trial. J Am Geriatr Soc 2012;60:16-23.

73. Cermak NM, Res PT, de Groot LC, Saris WH, van Loon LJ. Protein supplementation augments the adaptive response of skeletal muscle to resistance-type exercise training: a meta-analysis. Am J
Clin Nutr 2012;96:1454-64.

74. Lee JS, Choi HS, Ko YG, Yun DH. Performance of the Geriatric Nutritional Risk Index in predicting 28-day hospital mortality in older adult patients with sepsis. Clin Nutr 2013;32:843-8.

75. KDIGO 2012 clinical practice guideline for the evaluation and management of chronic kidney disease (Chapter 3). Kidney Int Suppl 2013;3:73-90.

76. Lee SY, Yang DH, Hwang E, Kang SH, Park SH, Kim TW, et al. The prevalence, association, and clinical outcomes of frailty in maintenance dialysis patients. J Ren Nutr 2017;27:106-12.

77. Chowdhury R, Peel NM, Krosch M, Hubbard RE. Frailty and chronic kidney disease: a systematic review. Arch Gerontol Geriatr 2017;68:135-142.

78. Koo JR, Yoon JW, Kim SG, Lee YK, Oh KH, Kim GH, et al. Association of depression with malnutrition in chronic hemodialysis patients. Am J Kidney Dis 2003;41:1037-42.

79. Mokdad AA, Lopez AD, Shahraz S, Lozano R, Mokdad AH, Stanaway J, et al. Liver cirrhosis mortality in 187 countries between 1980 and 2010: a systematic analysis. BMC Med 2014;12:145.

80. Dasarathy S. Consilience in sarcopenia of cirrhosis. J Cachexia Sarcopenia Muscle 2012;3:225-37.

81. Hanai T, Shiraki M, Nishimura K, Ohnishi S, Imai K, Suetsugu A, et al. Sarcopenia impairs prognosis of patients with liver cirrhosis. Nutrition 2015;31:193-9.

82. Nishikawa H, Shiraki M, Hiramatsu A, Moriya K, Hino K, Nishiguchi S. Japan Society of Hepatology guidelines for sarcopenia in liver disease (1st edition): recommendation from the working group for creation of sarcopenia assessment criteria. Hepatol Res 2016;46:951-63.

83. Ooi PH, Gilmour SM, Yap J, Mager DR. Effects of branched chain amino acid supplementation on patient care outcomes in adults and children with liver cirrhosis: A systematic review. Clin Nutr ESPEN 2018;28:41-51.

84. Kitajima Y, Takahashi H, Akiyama T, Murayama K, Iwane S, Kuwashiro T, et al. Supplementation with branched-chain amino acids ameliorates hypoalbuminemia, prevents sarcopenia, and reduces fat accumulation in the skeletal muscles of patients with liver cirrhosis. J Gastroenterol 2018;53:427-37.

85. Uojima H, Sakurai S, Hidaka H, Kinbara T, Sung JH, Ichita C, et al. Effect of branched-chain amino acid supplements on muscle strength and muscle mass in patients with liver cirrhosis. Eur J Gastroenterol Hepatol 2017;29:1402-7. 